\title{
REPENSAR A CIDADE: A DIMENSÃO ONTOLÓGICA DO URBANO**
}

\author{
Daniel Hiernaux*
}

\begin{abstract}
"Não tratar de encontrar muito cedo uma definição da cidade; é

um assunto muito vasto e há muitas possibilidades de se equivocar"

Georges Perec: Espécies de espaços
\end{abstract}

(1999:71)

\section{Introdução}

Hoje quando as cidades mudam tão velozmente quanto as sociedades, surge a impressão de que todo o conhecimento que a humanidade acumulou sobre a história das mesmas, está se erodindo pela intensidade e quase, pela própria violência do processo de mudança.

Os exemplos surgem em abundância: entre as redes que cruzam de forma invisível os espaços urbanos para distribuir informação, ou às vezes mentiras ou novas lendas urbanas (como a notícia da existência de uma banda denominada "sangue" na Cidade do México ao final do ano de 2005), até a proliferação de conjuntos cercados por muros onde encerram seus medos os que têm o que os demais sentem saudades, são muitas as facetas destas "novas cidades" que se apresentam a nossos olhos. Mais ainda, resulta impressionante observar que as mesmas tendências, os mesmos medos, as mesmas ilusões de modernidade, avassalam a todos os territórios do mundo.

Uma pergunta, entretanto, se impõe aos que pretendem superar a profusão dos elementos visíveis para interrogar a essência do fenômeno atual: Como interpretar estas mudanças? Como reconstruir a urdidura de um tecido do qual só vemos os fios exteriores e o acabado que nos deixam ver?

As leituras da cidade atual propostas agora pelos analistas são muito diferentes e respondem a correntes de pensamento ainda mal estabelecidas ou pouco consolidadas depois da derrubada dos grandes discursos: desde as propostas pós-marxistas de David Harvey (2003) ou Neil Smith (1996), passando pela sociologização do discurso da globalização que sugere a obra de Saskia Sassen (1991), até as versões mais centradas na cultura que propõem Nestor García Canclini (2004) ou Armando Silva (1992), estamos diante de uma inescusável multiplicidade de vozes que pretendem decifrar a cidade contemporânea. Todas, à sua maneira e no marco das limitações mas também das potencialidades que trazem consigo de seus enfoques, aportam algo ao estudo da cidade atual.

Todas remetem a uma porção da realidade, a aquelas dimensões que se presumem essenciais para entender a cidade de hoje, sejam as migrações internacionais, os imaginários urbanos, o peso das corporações internacionais ou o modo de governar, para mencionar somente algumas. Dimensões, todas elas, que se derivam da ênfase momentânea que os intelectuais pressentem necessária dar a algum elemento em especial, quando já se

\footnotetext{
*Professor Pesquisador Titular e Coordenador do Curso de Geografia Huamana da Universidade Autônoma Metropolitana: Unidade Iztapalana, Cidade do México.E-mail: danielhiernaux@yahoo.com.mx

**Traduzido por Rodolfo Pereira das Chagas, Mestrando em Geografia pelo Departamento de Geografia da FFLCH - USP. E-mail: rodogeo@ig.com.br
} 
esfumaram as frases feitas, as explicações formalizadas que tornaram mais fácil, embora menos criativo, o trabalho das ciências sociais desde alguns qüinqüênios.

Por isso, as explicações são múltiplas, a realidade fragmentada, peças de um quebracabeça sempre não-concluído, sempre renovado, parecido ao tecido de Penélope. Por isso também, os leitores destas análises podem passar, avidamente, de uma leitura a outra, de uma interpretação aparentemente sem falha a outra que, em questão de minutos, se torna inconfundivelmente a mais acertada, até que a sofisticação de uma nova proposta, apaga as anteriores, como uma maré.

A riqueza deste processo caótico não deve passar desapercebida: em vez de discursos contundentes que explicam "tudo" a partir de algumas afirmações decisivas, a multiplicidade de ensaios interpretativos induz a emergência de diversos marcos históricos, como pontas de iceberg no meio do mar de nossa incapacidade para entender a cidade contemporânea. O valor do caótico, do múltiplo, da própria diversidade, até nas explicações intelectuais, é sem sombra de dúvidas, uma grande virtude de nossos tempos.

Poucos autores, entretanto, enfrentam uma pergunta fundamental, aquela que deveria preceder a todas as demais sobre temas concretos: Estamos ainda frente ao que tradicionalmente se tem chamado de "cidade"? ${ }^{1}$ Efetivamente, seguimos usando a voz "cidade" para qualificar estas urbanizações extensas, esta "cidade difusa", estas formas de ocupação do espaço inovadoras que impactam nosso intelecto e nossos sentidos, como se nada tivesse mudado desde a "polis" grega, desde o nascimento do burgo feudal na Idade Média européia, ou desde a cidade industrial do século XIX. Em outras palavras, a voz que descreve as formas de ocupação do espaço pareceria ter se congelado enquanto que, mediante a realidade, ninguém poderá negar a profunda transformação da própria "cidade".

Não é que não floresceram as propostas de denominação, em uma sorte de esforço desesperado para agarrar um processo através de lhe dar um nome: citávamos, há alguns parágrafos, a denominação de "cidade difusa", uma "apelação controlada" recentemente posta no mercado, mesmo que a história do pensamento urbano nos permita acumular muitas denominações a mais, desde a "Groszstadt" simmeliana (Simmel, 1986), passando pela "megalópole" gottmaniana (Gottman e Harper, 1990), até chegar aos ensaios contemporâneos, como a "metápole" (Ascher, 1995), "edge city" (Garreau, 1991) e outra "exópole" (Soja, 2000).

Apesar deste florescimento certamente ilustrativo de denominações, ficamos pouco satisfeitos com o que se tem aportado para definir a cidade ela mesma, para ir à essência mesma de um fenômeno que, não por ser milenar, deixou de se recriar permanentemente, ou talvez de desaparecer para dar lugar a outras formas de ocupação do espaço. Alguém confirmou que o modelo "cidade" tinha que ser eterno?

Estes temas integram a questão fundamental que trataremos nas páginas a seguir. Em certo sentido, o que pretendemos fazer - modestamente - é uma reflexão ontológica sobre a cidade, sobre a essência mesma do que se tem considerado, desde o renascimento do processo urbano na Europa medieval, como uma "cidade".

Os aportes sobre o tema provem, essencialmente, de autores que fizeram da cidade, o tema da uma meta-reflexão, mais próxima à filosofia do que aos estudos urbanos tradicionais.

\section{I}

Definir a cidade, indagar na essência ontológica da mesma, nos obriga a partir, em primeira instância, de uma reflexão sobre sua definição tradicional: para a maior parte dos autores que estudaram a cidade e pretenderam defini-la, a cidade se caracteriza pela 
concentração de uma certa quantidade de população, uma certa densidade física, a presença de atividades não diretamente ligadas à produção do campo e um modo de vida distinto do que prevalece nas zonas que - em forma de antinomia - se qualificaram como "rurais". O anterior já foi amplamente estudado e criticado por Louis Wirth desde 1938 (Wirth, 1988 [1938]).

Este tipo de definição, quer dizer um conjunto de definições aparentadas, remete a quatro campos disciplinares: a demografia, o urbanismo, a economia e a cultura. Muitos aspectos, entretanto, têm sido isolados por este tipo de enfoque, de tal situação de poder chegar a definições relativamente simples, acessíveis a todos e, sobretudo, mensuráveis e comparáveis internacionalmente. É então possível, empreender uma tarefa de comparação internacional dos graus de urbanização.

Para se conseguir o propósito anterior, o q se isolou não é nada secundário: temas tais como a organização social que remete à sociologia, assim como os aspectos subjetivos, tais como a formação dos imaginários que, se bem entra na dimensão cultural, não aparecem com freqüência nas definições de cidade. Os temas e campos do conhecimento, esquecidos ou omitidos nesta definição, são certamente muito mais importantes que os aproveitados. Não faltaram autores que, de uma maneira ou outra, se remeteram a estes e outros elos perdidos da análise da essência da cidade, como a política (em Weber, 1964; Kropotkine, 2003 ou Pirenne, 1975 por exemplo) ou a relação com o ambiente/entorno (Bairoch, 1990) mas, claramente não são os aportes considerados como os mais significativos e menos ainda são os de uso comum.

O que definitivamente sobressai de tudo isso, é a ausência de uma dimensão subjetiva nas definições tradicionais da cidade: centramse no material ou no visível, no supostamente objetivo, submetido aos critérios da razão positiva. Assim é então possível definir a cidade a partir de seu tamanho, critério bem conhecido pelos organismos que trabalham o demográfico, ou o econômico, por exemplo. Possivelmente, o exemplo mais completo e sofisticado que temos a este respeito no México é o trabalho de Luis Unikel em sua destacada obra sobre o Desenvolvimento Urbano do México (Unikel, 1976).

Isto é suficiente? Não consideramos assim. A complexidade das cidades supera o marco estreito de suas dimensões demográficas, morfológicas ou econômicas. As fronteiras entre o urbano e o rural se tornam cada vez mais frágeis à luz de uma crescente "urbanização do campo" que, singularmente, apaga de maneira progressiva os limites entre os modos de vida urbanos e rurais, pelo menos segundo os critérios tradicionais de delimitação entre ambos campos.

A pergunta é então: o que faz com que uma cidade seja uma cidade? Ou, em outras palavras, qual é a essência própria do feito urbano?

A esta pergunta nos aproximaremos nas páginas a seguir.

\section{II}

Proporemos uma definição da essência do urbano que levará em conta três categorias fundamentais: o labiríntico, o fugaz e o fortuito. Estas são três figuras metafóricas essenciais a partir das quais se pode desvelar a essência da cidade. São em essência metafóricas, porque representam mais um estado "absoluto" inatingível em forma total, que uma realidade concreta. O labiríntico não remete à obrigação de que a cidade se trace como um perfeito labirinto como o que se encontra inscrito no chão da catedral de Chartres. Tampouco o fugaz implica que tudo se desvaneça instantaneamente, mas sim que uma característica essencial do urbano é a ausência de duração, a volatilidade das coisas, as pessoas, as ações e os pensamentos. Finalmente, o fortuito não implica a ausência de 
organização nem de instituições, quando sabemos que, desde a Idade Média, as instituições foram decisivas para impulsionar o novo auge urbano (Pirenne, 1975; Weber, 1964); melhor se remete ao caráter caótico, espontâneo de muitos eventos urbanos.

Passaremos então a tratar de discernir cada uma das categorias antológicas que acabamos de mencionar e explicar de que maneira são essenciais para a definição do urbano.

\section{A figura do Labirinto}

O labirinto é uma das figuras mais enigmáticas que tenha oferecido a iconografia humana. Desde épocas muito antigas se encontra representado pelas sociedades humanas, assim como transformado em uma figura, uma morfologia particular da mitologia das sociedades antigas. É uma figura atrativa e complexa apesar de certa obviedade: a obrigação de encontrar um percurso em um entrelaçado de vias fechadas.

Michel Foucault expressa, acerca do labirinto que não é o lugar onde as pessoas se perdem, mas sim do qual se sai sempre perdido (Foucault, citado por Attali, 1996:209). Entrar em um labirinto, corresponde metaforicamente a empreender uma viagem mental não evidente, construída por avanços e retrocessos, que implica também um processo de memorização para encontrar o caminho da saída.

O homem moderno, o homo urbanus, o que vive na cidade, é quem, percebendo a complexidade do mundo atual, não trata de solucionar sua vida cotidiana a partir de traçados retos e decisões irrevogáveis, mas sim que assume um percurso labiríntico através do mundo da cidade. Este andar não determinado, não reflete uma incapacidade para encontrar o caminho reto, mas sim uma capacidade adaptativa quase genética, que faz que o homem moderno seja justamente um homem sábio. A sabedoria, não se encontrando no respeito das tradições, das normas e pautas estabelecidas desde tempos imemoriais, mas sim na capacidade da se adaptar, de encontrar um caminho diferente cada vez que se apresenta uma nova situação (uma esquina do labirinto, onde se tem que definir o caminho a seguir) é, em essência, a sabedoria do nômade (Attali, 2003).

A cidade é objetivamente uma figura metafórica do labirinto, ou também, e o pensando como espelho, o labirinto é a metáfora da cidade. Proliferaram-se as cidades de traçado regular e simples de interpretar, mas não é a forma material à qual nos referimos, mas sim ao sentido da própria abordagem da cidade.

A cidade é antes de tudo uma forma sócio-espacial cuja interpretação, tanto pelo habitante como pelo analista, requer um andar labiríntico: a complexidade se aninha na cidade e a transforma em um tecido de caminhos mentais e físicos que obriga os vai-vem, retrocessos, avanços e raras vezes, a chegada a uma saída evidente.

Regressando à aparente transparência para o habitante da cidade ortogonal, é possível e realista pensar que não é o caminho reto sempre a melhor via. Como o sublinha Jacques Attali: "Até as cidades mais artificiais nunca puderam se desfazer do labirinto: a vida não está feita de linhas retas" (Attali, 1996: 135). O medo a certos espaços pouco transitados, a afetividade ligada a certos espaços frente aos quais nos agrada passar, assim como muitos comportamentos modelados por nosso inconsciente ou por nossos desejos, atuam como uma situação de força mental para nos desviar do caminho reto. Obrigam-nos a seguir, inconscientemente, os ditados do labirinto; como sublinha Michel Roux, "o imaginário está no coração das 'realidades' geográficas" (Roux, 1999: 32).

A cidade de origem européia é, antes de tudo, labiríntica em seu traçado. O discurso da racionalidade proposto por Hippodamo de Mileto em sua intenção de impor o traçado ortogonal dos assentamentos do homem, foi pouco 
escutado na vida cotidiana das sociedades tradicionais. (Paden, 2001).

Nos primórdios da cidade moderna, na ur-modenirdade como a qualificou Walter Benjamin, a figura do labirinto volta a se impor com força através da construção das passagens cobertas de Paris, e em muitas cidades do mundo, onde esta forma arquitetônica-urbana se repetirá de maneira mais ou menos similar. Também Benjamin integra a figura do labirinto ao seu estudo sobre as passagens, através da montagem literária, que implica numerosas bifurcações mentais, algumas inclusive, pouco evidentes para o leitor. Finalmente, para Benjamin a cidade também é um labirinto como assinala Frisby: "...Benjamín concebia já a cidade de Paris como um labirinto e a passagem como um labirinto que continha a 'paisagem primitiva do consumo'" (Frisby, 1992: 346). Assim, evidencia-se que o labirinto não é uma figura pré-moderna, mas sim que foi retomada em suas formas básicas, pela modernidade.

Pelo contrário, a cidade moderna, de cunho anglo-saxônico, pareceria ter assumido rapidamente o traçado em forma de tabuleiro de damas, de tal maneira que o caráter labiríntico da cidade se esfumou. Como observa Jackson (1994), a maneira euclidiana de se situar no espaço tem sido amplamente aceita pela sociedade norte-americana, a qual assumiu a idéia de que a cidade deve ser transparente, evitando as brechas, os cantos, espaços neutros, impasses e outras formas de organização espacial que se encontram extensamente nas cidades tradicionais européias: a metáfora do labirinto se perdeu, diante da racionalidade irrepreensível do capitalismo protestante, e sabemos a que grau este modelo urbano se expandiu ao longo do mundo.

\section{A tirania do fugaz}

O tempo das sociedades rurais tradicionais difere sensivelmente das temporalidades do mundo urbano. A cidade implica movimento, mas talvez, sobretudo, velocidade. Os ritmos lentos da transformação das sociedades tradicionais remetiam a uma vida tranqüila, ao peso da tradição, à onipresença da memória e da continuidade que impunham as mesmas formas e os mesmos espaços de vida, de geração em geração. Em outras palavras, as possibilidades de mudança erma poucas e se se manifestavam, isso era a longo prazo.

Pelo contrário, a cidade implicou rapidamente a imposição de um ritmo muito diferente marcado pela velocidade das ações e a escassa transcendência temporal dos eventos $^{2}$. Certamente, a construção da cidade denotava sempre a permanência, como no caso da lenta construção das catedrais, mas até assim, os críticos da arquitetura evidenciaram como se transformava o estilo construtivo ao longo do processo de edificação, permitindo que a transformação pudesse e devesse ser lida na mesma pedra.

A vida urbana, por sua parte, esteve marcada, desde seu princípio, por outra temporalidade, cuja racionalidade se pode entender pelo passo da comunidade a associação, no sentido que desenvolveram Tönnies (1979) e Simmel (1986), entre outros. Enquanto que a presença da comunidade implicou que as relações sociais sempre estivessem marcadas pela onipresença do passado no presente (refletido nos costumes, normas e rituais precisos), a associação se alcança sobre a base de um acordo entre partes que não tem mais objeto que cumprir com um fim determinado: não existe, portanto, uma tradição tão forte, os costumes podem se modificar por exemplo, na medida em que a associação se torna melhor sob novos parâmetros.

Um dos parâmetros essenciais da associação é a abstração da riqueza, que de ser contabilizada em bens materiais, se transforma na imaterialidade do próprio dinheiro.

Este suporte das transações (o dinheiro), mas também transformador potente 
das relações sociais, se generaliza nas cidades que inventaram o cheque e posteriormente as formas magnéticas de dinheiro, permitindo assim a fugacidade dos intercâmbios, sua volatilidade graças a um suporte inodoro e aparentemente intranscendente das transações.

Georg Simmel tratou de forma magnífica esta transformação das relações no entorno urbano, mostrando que a vida urbana implica o encontro fugaz entre as pessoas, sem que isso leve à criação de obrigações mútuas. Na cidade, prefere-se a velocidade e a mudança à duração e à permanência, comprovando a instabilidade da residência, a mudança de trabalho, a seleção de atividades lúdicas, assim como a instabilidade da família. A exacerbação da tendência ao fugaz foi amplamente demonstrada pelos sociólogos urbanos, que evidenciam como se tem manifestado a redução da fidelidade a uma residência, a um lugar de compras, às relações sociais, e como se criaram gêneros de vida cada vez mais efêmeros: é o que Bauman qualifica como "modernidade líquida" (Bauman, 2003).

Em outro lugar, também tratamos de evidenciar que existe uma nova geografia do fugaz, já que esta qualidade não somente se refere aos encontros ou aos intercâmbios, mas também que concerne aos espaços (Hiernaux, 2006). O fugaz não é somente uma imposição tecnológica como, por exemplo, no uso de aparelhos de telecomunicações. Tornou-se uma forma de viver, uma capacidade nova de exercer ações no tempo: é também uma demanda social crescente (Hiernaux, 2005).

O fugaz não é só demandado, é também o que se constitui de forma talvez contraditória, com o que se costumava ver pelo passado, uma oferta concreta das instituições: desfiles (As chamadas "parades" em inglês e francês) oficiais e corporativos, movimentos fugazes propostos por grupos organizados, eventos instantâneos organizados pela Internet entre pessoas que não se conhecem, tudo isso reflete uma penetração crescente do fugaz na vida urbana, sem que se ofereça muita resistência a esse respeito.

O fugaz se torna assim uma característica dominante da vida urbana, e isso se expressa em todas as esferas do cotidiano, como certos relatos sobre sexualidade 0 retratam.

\section{A riqueza do fortuito}

Associa-se à fugacidade, de forma evidente, o caráter cada vez mais fortuito da vida urbana, também resultado da evolução das cidades em si. Se o labirinto é a representação metafórica da cidade, então não se pode duvidar que não se sabe o que aparecerá ao virar a esquina. A cidade oferece, então, novas possibilidades a cada cruzamento de ruas, seja no sentido tradicional, de uma variedade de oferta (Remy, $1966^{3}$ ) seja desde a perspectiva do desenvolvimento pessoal do indivíduo. Que o ar da cidade se faz livre dizia Robert Park ("Stadtlucht mach frel') parece uma evidência, mas que, além disso, a liberdade surge a partir da variedade de possibilidades que oferece o fortuito, é a observação complementar que consolida o proposto por este sociólogo. Jacques Lévy observa também que: "a cidade oferece, justamente pela densidade de sua diversidade, a possibilidade do que se pode chamar em inglês de "serendipity" - uma palavra que gosto muito: quer dizer que se encontra 0 que não se buscava" (Lévy, 2003: 83).

O fortuito não implica que a cidade funcione caoticamente, em cujo caso tudo poderia ocorrer, mas sim que a concentração de indivíduos com experiências e trajetórias distintas implica que do encontro de tantas diferenças, sempre pode surgir algo novo, inesperado, fortuito. Neste sentido, a cidade é berço de inovações porque reúne uma multiplicidade de experiências humanas que, situadas em um substrato labiríntico, marcado pela fugacidade do que ali ocorre, permite uma situação de combinações no infinito de eventos.

Então, o fortuito é uma dimensão incontrolável do urbano, fonte de inovações e 
de uma reconstrução constante. Isto permite ao escrito Joseph Roth, assinalar que se torna impossível descrever uma cidade de maneira definitiva, como parece que queriam fazer os guias turísticos em certos relatos de viagem: "Os livros de viagem estão ditados por um espírito estúpido, incapaz de crer na variabilidade do mundo. [...] O 'bom observador' é o informador mais triste. Registra tudo que esteja sujeito a mudanças com os olhos bem abertos mas rígidos" (Roth, 2000: 9).

Não há lugar a dúvidas que o fortuito representa uma riqueza inesgotável das cidades. É uma das principais fontes que seguem sendo atrativas para muitos, mesmo tendo outras facetas que são dificilmente suportáveis. O fortuito oferece uma qualidade extraordinária à vida urbana, a transforma num sempre recomeçar, apesar dos inegáveis elementos rotineiros, que comportam a vida cotidiana.

Assim, o fortuito é o que permite as pequenas transgressões, as mínimas subversões que aliviam o peso da rotina, da repetição do já conhecido: O caráter fortuito dos eventos na cidade é a pimenta da dolorosa experiência da rotina.

Sobre o fortuito se constrói a inovação social, a capacidade das cidades de se constituírem em territórios do moderno. Como já assinalara Charles Baudelaire, a modernidade se baseia no fortuito. Mas também poderíamos agregar que a cidade sem o fortuito seria um receptáculo vazio de nossas vivências, um simples contêiner de fatos e objetos, um suporte material da vida, o que - obviamente seria impossível de se viver.

\section{III}

As três características essenciais que apresentamos nas páginas anteriores - o caráter labiríntico, a fugacidade e a essência fortuita do urbano - podem ser vistas como as três dimensões centrais a partir das quais podemos construir a ontologia da cidade.
Estamos longe, pois, das definições tradicionais da cidade: a quantidade de população, sua densidade física ou a presença de atividades não rurais. Essas já não são suficientes para que um espaço seja urbano. Tudo isso não significa mais que intentos sejam técnicos, mas sim tecnocráticos, que reduzem a essência do urbano a algumas características essencialmente físicas ou econômicas. Com base nos critérios anteriores, é evidente que o estudo da cidade não passa por definir níveis de cidades por tamanho, por estudar variações de densidade do centro à periferia, ou por estudar as novas profissões que surgem da atual "globalização", entre outras análises possíveis.

Mas talvez devamos começar uma reflexão que pareceria muito mais significativa e que já vem sendo empreendida parcialmente por alguns autores. Esta é a de redefinir a cidade em outro sentido, e talvez, particularmente, a partir destas figuras metafóricas que compõem a estrutura, os pilares, da construção do próprio conceito de cidade.

Falar da cidade difusa, com faz por exemplo Giuseppe Dematteis (1998), ou de exópole (Garreau, 1991), de metápole (Ascher, 1995), entre outras vozes, umas com mais êxito que outras, não resolve o problema, ou melhor, o agrava, porque estas expressões partem da idéia de que toda aglomeração humana com certas características oficiais, segue sendo, de certa forma, uma cidade porque somente se estudam as variações de uma forma de "cidade" pré-determinada, ao invés de se interrogar sobre a essência mesma da "cidade como ser", quer dizer, empreender a construção de uma ontologia da cidade. Esta tarefa, possivelmente, não faria mais que derrubar muitos dos discursos sobre a cidade contemporânea.

A tríade "labiríntico-fugaz-fortuito" não é uma simples justaposição de "ocorrências" bonitas pelas quais se poderia repensar a cidade. Esta tríade permite uma redefinição ontológica sobre o que a cidade é em sua 
essência, o que faz, em outras palavras, que uma cidade seja uma cidade e não uma simples aglomeração de pessoas com certas atividades sobre um território dado, sob uma determinada morfologia espacial.

Uma cidade, pelo menos no sentido que se atribuiu tradicionalmente ao conceito, tem que ter as três características mencionadas. Mas, além disso, elas têm que possuir essas características de forma simultânea e articulada. Não há possibilidade de que um labirinto sem o caráter fortuito e sem a fugacidade constitua uma cidade. Tampouco é possível que os eventos de caráter fortuito e/ou fugaz possam se constituir em uma representação da cidade, se não existe o labiríntico que é seu substrato, não somente físico mas também mental.

De fato as três caracterizações falam do mesmo, mas se referem a campos distintos. O labiríntico remete ao espacial desde o geográfico até a organização do espaço mental (o labiríntico dos sonhos e dos imaginários). O fugaz se refere ao temporal, e o fortuito ao social. Estamos falando, então, de uma complementaridade real, em três campos articulados e dificilmente separáveis, de uma "certa" característica que é a marca de referência que define a cidade. Em boa medida, falamos da não linearidade do espaço, do tempo e das ações sociais, da ausência de um traçado confiável, permanente, seguro para nossas ações no tempo e no espaço.

Isto é o que distingue a cidade do "campo" ou, melhor dizendo, das formas distintas de articulação entre a natureza e a sociedade que costumavam se dar no passado. A comunidade, em suas diversas formas de inscrição social, desde o calpulli pré-hispânico, até as vilas tradicionais européias ou as aldeias africanas, não ofereceu nem oferecerá - para o bem ou para o mal - a diversidade de espaços, de possibilidades nem de inovações que ofereceu, e segue oferecendo, a cidade desde seus primórdios.

A questão que pode se colocar também, desde uma perspectiva histórica, é se certas formas de assentamentos, como Tenochtitlán, entre outros, cabem nesta formulação da essência da cidade que acabamos de propor. Não nos cabe responder esta pergunta, mas podemos afirmar que muitas formas atuais de assentamento humano, como as intermináveis periferias das metrópoles mundiais, e particularmente as nossas no México, distam de ser labirínticas, de oferecer fugacidade e o caráter fortuito que consideramos como essência ontológica da cidade.

O debate não de se focar na morfologia da cidade, e colocamos por outro lado, que o modelo de urbanização atual dista de ter as condições para que possa ser qualificado como urbano. A questão é, então, a de reconhecer que talvez estejamos entrando numa fase de "pós-cidade" onde reina a urbanização sem cidade. Isto é o que insinuaram, em forma profética, autores como Françoise Choay (1970) ou Murray Bookchin (1989), há mais de trinta anos.

Tampouco é aceitável que todo o urbanizado não seja cidade. A cidade perdura, em sua essência ontológica tradicional, mas é evidente que foi substituída (talvez desde os anos sessenta?) por uma urbanização que não é cidade, mas "outra coisa" da qual é pertinente fazer a ontologia e Ihe dar um nome, batizá-la, o que até agora não foi feito, talvez pelo afã de seguir discutindo sobre as formas de cidade.

Significativamente, muitas cidades que perduraram como tais, se rodearam destas urbanizações intermináveis. Inclusive, encontramos um verdadeiro interesse em muitos de seus habitantes por empreender um "regresso à cidade" (Bidou, Hiernaux e Rivière d'Arc, 2003) que, com freqüência, serve mais para desvirtuar o espaço urbano ainda existente que para assegurar a permanência da cidade.

Fenômenos como a "gentrificação" ou a "turistificação" se fizeram presentes em muitas cidades, desenvolvidas ou não. Mas estes processos, fruto de uma visão nostálgica, mesmo que não forçosamente negativa da cidade, não apóiam sua permanência, mas ofuscam as possibilidades de sustentá-las como tais. Assim, os centros urbanos costumam se 
tornar museus semi-vivos para a felicidade dos turistas, ou lugar de residência das novas burguesias que, antes de tudo, reclamam que se eliminem todas as condições do fortuito e do fugaz, como podem ser os "mal-viventes, comerciantes ambulantes, prostitutas e demais vagabundos".

Uma cidade que talvez conserva o caráter labiríntico de sua planta antiga, é onde não se permite e inclusive se tem um medo exagerado a tudo o que não é controlado, datado, conhecido (vide o auge da cidadefilmada dia e noite por câmeras de vigilância); este medo é recorrente em muitas cidade cujos centros estão passando pelo processo de elitização ou gentrificação, ou seja, México, Londres (a cidade mais controlada do mundo), Nova Iorque ou Paris: "Nada mal pode passar se nada fortuito de apresenta" parece ser o lema de nossas cidades "gentrificadas".

Talvez, então, é a Louis Wirth que devamos regressar para reencontrar esta "personalidade urbana" marcada pelo efêmero, o transitório, a complexidade e a mobilidade (Wirth, 1938), personalidade que distingue a cidade das massas informes, de nossas urbanizações "difusas" (Chadouin, 2005).

Nossas reflexões anteriores não somente se remetem à necessidade de uma reflexão filosófica, da qual estas notas são somente um esboço. Também poderiam ser matéria de uma política urbana mais inteligente e atenta à própria realidade, que reflita sobre a cidade de amanhã, para construí-la desde hoje.

\section{Notas}

${ }^{1}$ Donzelot, por exemplo, fala de uma "nova questão urbana" que surge tanto da expansão da cidade, como das novas formas de organização do espaço urbano, particularmente a partir das novas segregações voluntárias (Donzelot, 1999)

2 Neste sentido, a modernidade é, como bem assinalou Baudelaire, o transitório, o fugitivo, o contingente.

3 Em sua obra clássica sobre a cidade, Jean Remy (1966) havia colocado, há quase quarenta anos, que a variedade da oferta era uma dimensão essencial do urbano; embora o fizesse em termos essencialmente econômicos, a reflexão segue sendo pertinente e também premonitória para o mundo urbano atual.

4 Cabe recordar que esta expressão foi introduzida na teoria sociológica por Robert Merton em referência a "um dado imprevisto, anômalo e estratégico que se transforma por ocasião do desenvolvimento de uma teoria nova ou da ampliação de uma existente (...). Uma investigação encaminhada para comprovar uma tese lança um subproduto fortuito que influi em teorias que não se haviam tido em conta ao se começar uma investigação" (Merton, 1995: 181). 
